\title{
Dendritic Spines of CA1 Pyramidal Cells in the Rat Hippocampus: Serial Electron Microscopy with Reference to Their Biophysical Characteristics
}

\author{
Kristen M. Harris ${ }^{1}$ and John K. Stevens ${ }^{2}$ \\ 'Department of Neurology, Children's Hospital, Boston, Massachusetts 02115 and 2 Playfair Neuroscience Unit, University \\ of Toronto, Toronto, Ontario M5T 2S8, Canada
}

\begin{abstract}
Serial electron microscopy and 3-D reconstructions of dendritic spines from hippocampal area CA1 dendrites were obtained to evaluate 2 questions about relationships between spine geometry and synaptic efficacy. First, under what biophysical conditions are the spine necks likely to reduce the magnitude of charge transferred from the synapses on the spine heads to the recipient dendrite? Simulation software provided by Charles Wilson (1984) was used to determine that if synaptic conductance is $1 \mathrm{nS}$ or less, only $1 \%$ of the hippocampal spine necks are sufficiently thin and long to reduce charge transfer by more than $10 \%$. If synaptic conductance approaches $5 \mathrm{nS}$, however, $33 \%$ of the hippocampal spine necks are sufficiently thin and long to reduce charge transfer by more than $10 \%$.

Second, is spine geometry associated with other anatomical indicators of synaptic efficacy, including the area of the postsynaptic density and the number of vesicles in the presynaptic axon? Reconstructed spines were graphically edited into head and neck compartments, and their dimensions were measured, the areas of the postsynaptic densities (PSD) were measured, and all of the vesicles in the presynaptic axonal varicosities were counted. The dimensions of the spine head were well correlated with the area of PSD and the number of vesicles in the presynaptic axonal varicosity. Spine neck diameter and length were not correlated with PSD area, head volume, or the number of vesicles. These results suggest that the dimensions of the spine head, but not the spine neck, reflect differences in synaptic efficacy.
\end{abstract}

\footnotetext{
Received Sept. 22, 1988; accepted Jan. 12, 1989.

We thank Ms. Judy Trogadis for training the first author on the movie reconstruction system and for many interesting discussions. We also thank Dr. Charles Wilson for supplying K.M.H. with the software for the biophysical simulations, and $\mathrm{Mr}$. Greg Belmont for implementing and improving the ease of using this simulation software to make Figure 8. We are grateful to Ms. Linda Kirschner and Mr. Nariman Shambayati for writing the software system used to display and edit the 3-D reconstructions in the Image Graphics Laboratory (IGI.) at Children's Hospital. We thank Ms. Beatrice Tsao for her help with the graphics editing and Ms. Debbie Goldenberg for completing one of the reconstructions. Dr. D. Max Snodderly and Dr. Thomas Brown are appreciated for their insightful discussions of the results. Drs. Frances Jensen, Charles Stevens, Dan Johnston, and Charles Wilson are thanked for careful reading of an earlier version of the manuscript. This work was begun while K.M.H. was a postdoctoral fellow with Dr. Dennis Landis, and his suggestions during the early stages are appreciated. This work was supported by the Alfred P. Sloan foundation and NIH grant NS21184 (K.M.H.), MRC grant MT7345 (J.K.S.), NIH grant NS20820 (R. L. Sidman, P.I.), and by the Mental Retardation Center grant P30-HDI8655 from NICHD.

Correspondence should be addressed to: Kristen M. Harris, Ph.D., Department of Neurology, Enders 2, Children's Hospital, 300 Longwood Ave., Boston, MA 02115 .

Copyright (C) 1989 Society for Neuroscience $0270-6474 / 89 / 082982-16 \$ 02.00 / 0$
}

We suggest that the constricted necks of hippocampal dendritic spines might reduce diffusion of activated molecules to neighboring synapses, thereby attributing specificity to activated or potentiated synapses.

In an earlier study, we measured cerebellar dendritic spines through serial electron microscopy and 3-D reconstructions (Harris and Stevens, 1988b). Using published results from a biophysical simulation of charge transfer in passive dendritic spines (Wilson, 1984), we found that most of these cerebellar dendritic spines were insufficiently thin or long to reduce charge transfer to the recipient dendrite even if we accounted for the volume of the smooth endoplasmic reticulum in their necks. We also found that the dimensions of the cerebellar spine heads, but not the spine necks, were well correlated with other anatomical indicators of synaptic efficacy, including the area of the postsynaptic density (PSD) and the number of vesicles in the presynaptic axonal varicosity.

Here we present a similar description of dendritic spines in area $\mathrm{CA} 1$ of the rat hippocampus. Hippocampal spines are interesting because several reports have indicated that their shape or number might change in response to tetanic stimulation that induces long-term potentiation (for a review, see Desmond and Levy, 1988; Greenough and Bailey, 1988; and Harris et al., 1988). It has long been postulated that changes in the dimensions of spine necks could modulate synaptic efficacy and thus form a cellular basis for physiological plasticity or memory (e.g., Ramón y Cajal, 1891, 1911; Chang, 1952; Scheibel and Scheibel, 1968; Diamond ct al., 1970; Rall, 1970, 1974, 1978; Van Harreveld and Fifkova, 1975; Crick, 1982; Perkel, 1982-1983; Koch and Poggio, 1983; Turner, 1984; Coss and Perkel, 1985; Miller et al., 1985; Perkel and Perkel, 1985; Shepherd et al., 1985; Shepherd and Brayton, 1987; Rall and Segev, 1988).

We have computed relationships between hippocampal spines, their synapses, and their presynaptic axons to further evaluate 2 questions about spine function. These questions were discussed in detail in the earlier study of cerebellar dendritic spines (Harris and Stevens, 1988b). First, under what biophysical conditions are the spine necks sufficiently thin or long to reduce charge transfer from the synapse to the recipient dendrite ("resistance" function)? The hippocampal spine dimensions were tested with Wilson's (1984) biophysical simulation of passive spines and compared to the cerebellar dendritic spines. Second, does the lack of correlation between cerebellar spine neck dimensions and other indicators of synaptic efficacy also occur across hippocampal spines of differing shapes? Thus, might the 
spine neck constriction serve some other function, such as reducing diffusion between activated and unactivated synapses ("compartmentation" function; Shepherd, 1979; Horwitz, 1984; Gamble and Koch, 1987; Brown et al., 1988)? Preliminary results have been reported elsewhere (Harris et al., 1985; Harris and Stevens, 1988a).

\section{Materials and Methods}

Tissue preparation. Three male rats of the Long-Evans strain weighing $207 \mathrm{gm}$ (series 15, 16), $137 \mathrm{gm}$ (series 17, 18), and $310 \mathrm{gm}$ (series 21 , $22,24)$ were perfused through the heart under deep pentobarbital anesthesia with $2 \%$ paraformaldehyde, $2.5 \%$ glutaraldehyde, and $2 \mathrm{~mm}$ $\mathrm{CaCl}_{2}$ in $0.1 \mathrm{M}$ cacodylate buffer at $\mathrm{pH} 7.35,37^{\circ} \mathrm{C}$, and $4 \mathrm{psi}$. The brains were left undisturbed in the cranium for $1 \mathrm{hr}$, and then the hippocampus was removed.

For the first animal, the hippocampus was sliced transverse to its longitudinal axis at $400 \mu \mathrm{m}$ after a 2 -hr postfixation in the same aldehyde mixture and an overnight soak in buffer. These slices were then immersed for $1 \mathrm{hr}$ in $1 \% \mathrm{OsO}_{4}$, rinsed repeatedly in buffer, soaked for 1 $\mathrm{hr}$ in $1 \%$ tannic acid, rinsed in cacodylate and acetate buffers, soaked overnight at $4^{\circ} \mathrm{C}$ in $1 \%$ uranyl acetate followed by rinses and dehydration through graded alcohols, propylene oxide, and embedded in Epon. The blocks were trimmed to contain the hippocampal CA1 pyramidal cell bodies and their apical dendrites in stratum radiatum. Serial sections were cut at pale gold on a Reichert Ultracut E ultramicrotome (photographic series 15,16$)$.

For the second animal (photographic series 17 and 18), the whole hippocampus was postfixed in the aldehyde mixture for $2 \mathrm{hr}$ at $4^{\circ} \mathrm{C}$, stored in $0.1 \mathrm{M}$ cacodylate buffer for $2 \mathrm{~d}$, and then sliced at $400 \mu \mathrm{m}$. The slices were washed in cacodylate buffer, rinsed twice in distilled water, soaked for $1 \mathrm{hr}$ in $1 \% \mathrm{OsO}_{4}$ with $1.5 \%$ potassium, ferrocyanide, and rinsed twice in distilled water, and then dehydrated through graded ethanols, propylene oxide, and embedded in Epon. Blocks were trimmed to contain the same region of area CAl as in animal 1 and were serially sectioned at silver (photographic series 17, 18).

The hippocampus from the third animal was sliced at $400 \mu \mathrm{m}$ immediately after dissection. The slices were washed with agitation in buffer and then soaked for $1 \mathrm{hr}$ in $1 \% \mathrm{OsO}_{4}$ with $1.5 \%$ potassium ferrocyanide followed by $1 \mathrm{hr}$ in $\mathrm{OsO}_{4}$. Tissue sections were rinsed in buffer, soaked in $30 \%$ and $50 \%$ ethanol for $10 \mathrm{~min}$ each, immersed for $1 \mathrm{hr}$ in $1 \%$ uranyl acetate in $70 \%$ ethanol at room temperature, dehydrated, embedded in Epon, and serially thin sectioned at silver (photographic series $21,22,24$ ).

All 3 sets of serial sections ( 1 set from each animal) were mounted on Formvar-coated slot grids (Synaptek) and stained for $5 \mathrm{~min}$ with Reynolds' lead citrate. Each grid of each series was mounted in a grid cassette (Stevens and Trogadis, 1984) and stored in a numbered gelatin capsule. The series identification numbers reflect the sequential number assigned to each series that has been photographed in the laboratory, including all studies of hippocampus and cerebellum. Animals 2 and 3 were the same animals that were used to complete the $3-D$ reconstructions of dendritic spines on cerebellar Purkinje cells (Harris and Stevens, 1988 b). Comparisons of spine dimensions from the hippocampus and cerebellum are limited to these 2 animals.

Electron microscopy. The grid cassettes were mounted in rotating stages to obtain consistent orientation of sections on adjacent grids during photography at a JEOL $100 \mathrm{~B}$ electron microscope. Seven dendritic segments located approximately $200-250 \mu \mathrm{m}$ from the CA1 pyramidal cell layer in the middle of stratum radiatum were photographed through serial sections as follows: series 15,55 sections; series 16,62 sections; series 17,56 sections; series 18,71 sections; series 21,68 sections; series 22,79 sections; and series 24,89 sections (total $=418$ sections).

We chose to photograph these CA1 dendritic segments through serial sections instead of sampling a population of individual dendritic spines from many different dendrites for 2 practical reasons. First, this approach allowed us to choose a magnification $(\times 15,000-18,000)$ that was low enough that a single electron-microscopic negative contained the dendrites, all of their associated spines, and their presynaptic axonal varicosities, yet high enough that excellent resolution was obtained of the spines, the vesicles in the presynaptic axonal varicosity, and the PSDs. By positioning the cross-sectioned dendrite in the very center of the field on each serial section, we could avoid the very tedious process of reconstruction from montages. Second, to obtain the same number of spines from a larger population of dendrites would have required photographing several different fields through serial sections, or a single field at a very much lower magnification that could have compromised the accuracy of the reconstructions.

3-D reconstructions. The methods described in Stevens and Trogadis (1984) and Harris and Stevens (1988b) were used to obtain complete 3-D reconstructions from the CA1 dendritic segments and their presynaptic axonal varicosities.

Graphics editing. The procedures described in Harris and Stevens (1988b) were used to graphically edit each CAl dendritic spine into its head and neck compartments.

Computation of volumes, areas, lengths, and counts. Spine neck and head volumes, lengths and diameters, PSD areas, varicosity volumes, and the total number of vesicles in the presynaptic axonal varicosity were calculated in the same way that was described for the cerebellar dendritic spines in Harris and Stevens (1988b). The smooth endoplasmic reticulum appeared discontinuous in some sections of some hippocampal dendritic spines, and therefore a quantitative evaluation of its volume was not included here.

Section thickness determination. Initially, section thickness was assumed to be $0.1 \mu \mathrm{m}$ (series 15, 16), $0.07 \mu \mathrm{m}$ (series 17, 18), or $0.06 \mu \mathrm{m}$ (series $21,22,24$ ), based on the interference color of the sections floating on water in the boat of the diamond knife (Meek, 1976). The mitochondria in CA1 pyramidal cell dendrites are approximately cylindrical, so that an independent estimate of section thickness was obtained by measuring the diameters of longitudinally sectioned mitochondria at their maxima in single sections and comparing the measured diameter to the number of sections that the mitochondria appeared in (Harris and Stevens, 1988a). Section thickness was then calculated as:

Thickness $(\mu \mathrm{m} /$ section $)=$ measured diameter $(\mu \mathrm{m}) /$ number of sections

Using this formula, the average section thickness calculated for series 15 and 16 from 13 mitochondrial measures was $0.100 \mu \mathrm{m}$; for series 17 and 18 from 14 measures, it was $0.073 \mu \mathrm{m}$; and for series 21,22 , 24 from 18 measures, it was $0.055 \mu \mathrm{m}$. All were thus in close agreement with the estimates obtained by interference coloration of the sections.

Biophysicul modeling. The same methods that were used for cerebellar spine necks and heads were applied to determine whether the hippocampal spine heads were spherical and the spine necks were cylindrical (Harris and Stevens, 1988b). In addition, original software was obtained from Dr. Charles Wilson to test how the dimensions of passive dendritic spines might reduce charge transfer to the recipient dendrite (Wilson, 1984). This software was implemented to generate the curves illustrated in Figure $8, A, B$. A more detailed description of the interaction between spine dimensions and a full range of biophysical parameters is in preparation (G. C. Belmont and K. M. Harris, unpublished observations).

Statistical analyses. The RS1 statistical package (Bolt, Beranek and Newman, Cambridge, MA) was used to obtain correlations and comparisons described in the Results. For comparisons of mean values, the sample distributions were first tested for normality by the Wilkes-Shapiro test, and then the $F$ test for homogeneity of variance was applied. If these criteria were met, then a parametric $t$ test was applied to test differences between mean values. The nonparametric Mann-Whitney $U$ statistic for medians with equal dispersions was used for the comparisons if the distributions were not normal and their variances were not homogeneous.

\section{Results}

3-D reconstructions of dendritic segments from $C A 1$ pyramidal cells

Seven dendritic segments located approximately $200-250 \mu \mathrm{m}$ from the pyramidal cell layer in stratum radiatum were reconstructed through serial sections. The complete 3-D reconstructions of these dendritic segments are illustrated in Figure 1, where the individual dendritic spines are black thick lines and their dendritic shafts are thinner gray lines. These dendritic segments ranged in length from 5.9 to $12.4 \mu \mathrm{m}$ (Table 1). Their diameters were measured at the base of each dendritic spine and ranged between 0.32 and $0.85 \mu \mathrm{m}$ (Table 1). The total dendritic volumes and surface areas were computed by closing 


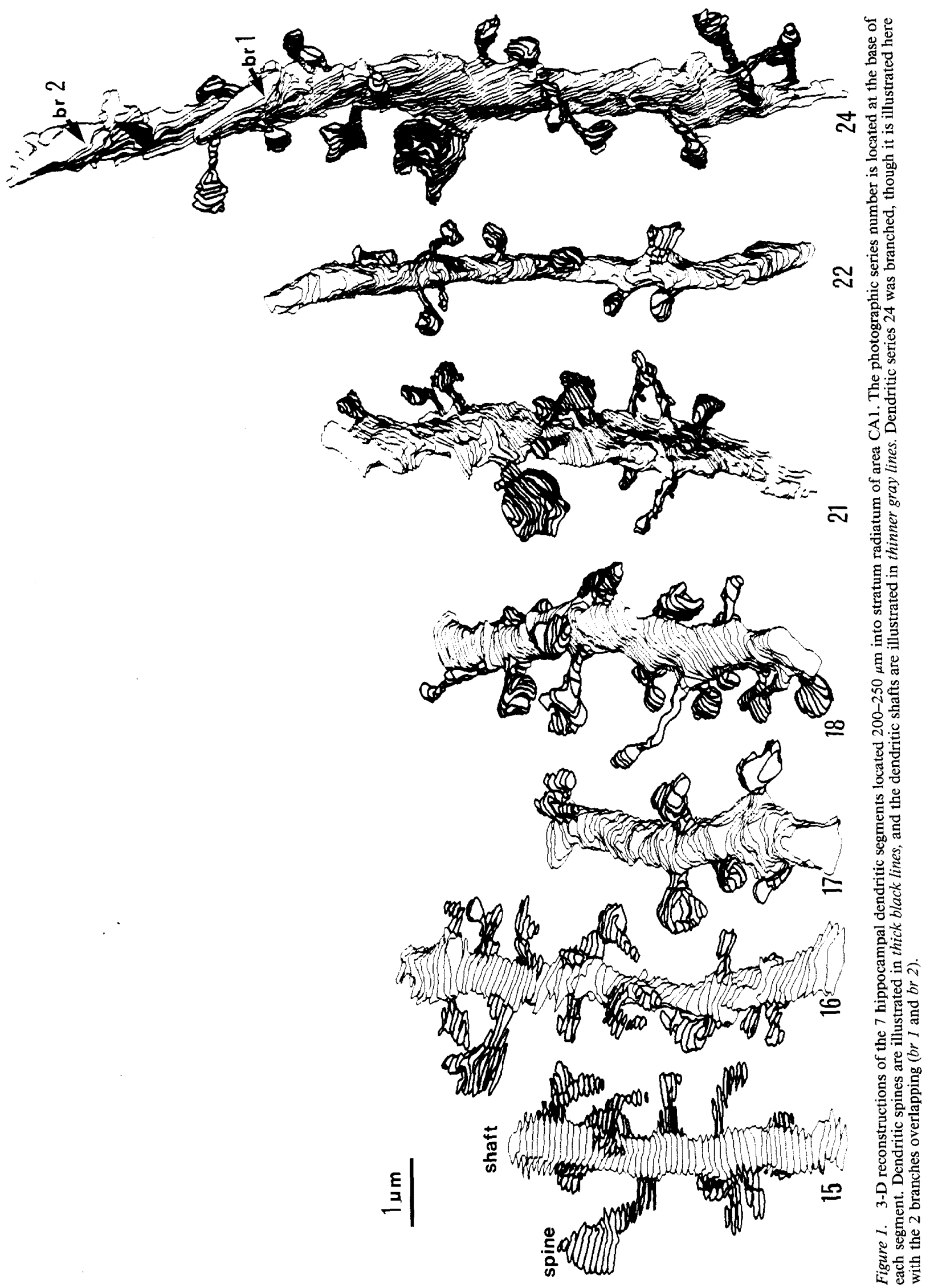


Table 1. Geometric characteristics and approximate spine densities for the 7 reconstructed dendritic segments

\begin{tabular}{|c|c|c|c|c|c|c|c|}
\hline \multirow[b]{2}{*}{ Series no. } & \multicolumn{4}{|c|}{ Dendrites } & \multicolumn{3}{|l|}{ Spines } \\
\hline & $\begin{array}{l}\text { Length } \\
(\mu \mathrm{m})\end{array}$ & $\begin{array}{l}\text { Diameter } \\
(\mu \mathrm{m})\end{array}$ & $\begin{array}{l}\text { Volume } \\
\left(\mu \mathrm{m}^{3}\right)\end{array}$ & $\begin{array}{l}\text { Surface } \\
\left(\mu \mathrm{m}^{2}\right)\end{array}$ & $\begin{array}{l}\text { No. } \\
\text { origins }\end{array}$ & $\begin{array}{l}\text { No. } \\
\text { complete }\end{array}$ & $\begin{array}{l}\text { No. } \\
\text { origins/ } \\
\mu \mathrm{m}\end{array}$ \\
\hline 15 & 5.9 & $0.56 \pm 0.10$ & 2.00 & 14.19 & 18 & 14 & 3.1 \\
\hline 16 & 9.7 & $0.47 \pm 0.09$ & 2.86 & 19.39 & 20 & 18 & 2.1 \\
\hline 17 & 7.4 & $0.71 \pm 0.09$ & 2.32 & 11.90 & 8 & 6 & 1.1 \\
\hline 18 & 8.5 & $0.65 \pm 0.09$ & 2.81 & 15.98 & 26 & 21 & 3.1 \\
\hline 21 & 10.7 & $0.59 \pm 0.07$ & 3.09 & 18.32 & 19 & 14 & 1.8 \\
\hline 22 & 11.2 & $0.41 \pm 0.04$ & 2.18 & 16.55 & 15 & 10 & 1.3 \\
\hline $24^{a}$ & 12.4 & $0.51 \pm 0.12$ & 4.52 & 26.25 & 24 & 20 & 1.9 \\
\hline Summary & $69.4^{*}$ & $0.32-0.85^{\wedge}$ & $2.82^{* *}$ & $17.51^{* *}$ & $130^{*}$ & $103^{*}$ & $2.0^{* *}$ \\
\hline
\end{tabular}

Totals $\left(^{*}\right)$, ranges $\left(^{*}\right)$ and averages $\left(^{* *}\right)$ in the Summary are across all 7 series.

${ }^{a}$ The dendrite of series 24 branched within the series. This analysis includes the main shaft and the length of one branch of this dendrite. Two complete spines were on the second dendritic branch to give a total of 20 complete spines for this series. The second branch was near the edge of the series, and hence portions were incomplete; thus, its volume and surface area could not be accurately computed.

the holes left at the origins of each of the edited spines. These measured volumes and surface areas were then compared to those that would be computed for a right circular cylinder with the measured dendritic diameters and lengths, where volume $=$ (pi) $r^{2} h$ and lateral surface arca $=2(p i) r h$. This comparison revealed no statistically significant differences between the measured and computed values, and hence these hippocampal dendrites can be treated as right circular cylinders for modeling.

Each protrusion from a dendrite was counted as a "spine origin" if a neck or other features of a spine could be identified in adjacent sections. A "complete spine" was fully contained within the photographic series. The density of dendritic spine origins ranged from 1.0 to 3.1 spine origins $/ \mu \mathrm{m}$, averaging 2.0 spine origins $/ \mu \mathrm{m}$ of dendritic length (Table 1 ).

\section{Electron microscopic description of hippocampal dendritic spine morphology}

Three dendritic spines of stubby, thin, and mushroom shapes are illustrated in Figure 2, $A-C$. These dendritic spines are all from series 21 , showing that the full range in spine shapes can occur along a short segment of dendrite. Dendritic spines of all shapes have asymmetric (type I) synapses with a thickened PSD adjacent to a widened cleft that is filled with dense staining material. The stubby and thin spines have continuous postsynaptic densities (Fig. 2, $A, B$ ), and the large, mushroom-shaped spines have PSDs that are perforated by electron lucent regions (Fig. 2, $C, D$ ). For all of the spine shapes, the presynaptic axonal varicosity contains round, clear vesicles. Most hippocampal dendritic spines contain some smooth endoplasmic' reticulum (SER) (Fig. 2, $A, C, E$ ). In the large, mushroom-shaped dendritic spines the SER is laminated with dense staining material and is called a "spine apparatus" (Fig. 2C). Some spines share their presynaptic axonal varicosity with other spines from different dendritic segments (Fig. 2C). The large, mushroom-shaped spines usually have a projection, a "spinule," into the presynaptic varicosity at some of the perforations in the PSD (Fig. 2D). Some long, thin spines also have small projections into neighboring axonal varicosities that form a double-walled vesicle in that axon, but do not form synaptic junctions with it (Fig. $2 E$ ).

\section{3-D reconstructions of dendritic spines from the $C A I$ pyramidal cell dendrites}

Each dendritic spine was first viewed attached to the dendritic shaft while the complete reconstruction was rotated about the dendritic longitudinal axis. This viewing was especially important for obliquely sectioned dendritic spines in order to achieve accurate editing at the junction between the spine neck origin and the dendritic shaft. After graphically removing each spine from the parent dendrite, individual spines were rotated about their $z$ axes to determine good viewing angles. Then front and back views of each spine were plotted, with hidden lines removed, using a Hewlett Packard plotter interfaced through the PANDORA software (Pearlstein et al., 1986). These 3-D plots were used as guides for graphically editing the spines into their head and neck compartments.

The 5 spines in Figure 3 are illustrated as 3-D reconstructions including the parent dendrite. Stubby dendritic spines were treated as "heads" because no constriction occurred in the neck (Fig. 3A). A spine with average neck and head dimensions is illustrated in Figure $3 B$.

\section{Branched spines, spinules, and double-walled vesicles}

Dendritic spines were referred to as "branched spines" if more than 1 spine emerged from a single protrusion of the dendrite and if this protrusion had dimensions in the range of single spine necks and did not contain microtubules, and therefore was not a small dendritic branch (Fig. $3 C$ ). There were 3 branched spines in these series. The heads of the branched spines were widely spaced in the neuropil and did not share the same axonal varicosity. On one branched spine, one of the branches shared its presynaptic axonal varicosity with an unbranched spine from a different dendrite.

The heads of large, mushroom-shaped spines had perforated synapses with spinules and usually occurred on short constricted necks (Fig. 3D; see also Fig. 2, $C, D$ above). Four large mushroom spines had spinules at the perforations in their synapses. Three thin spines had small projections, double-walled vesicles, from their necks into neighboring, nonsynaptic axons. 

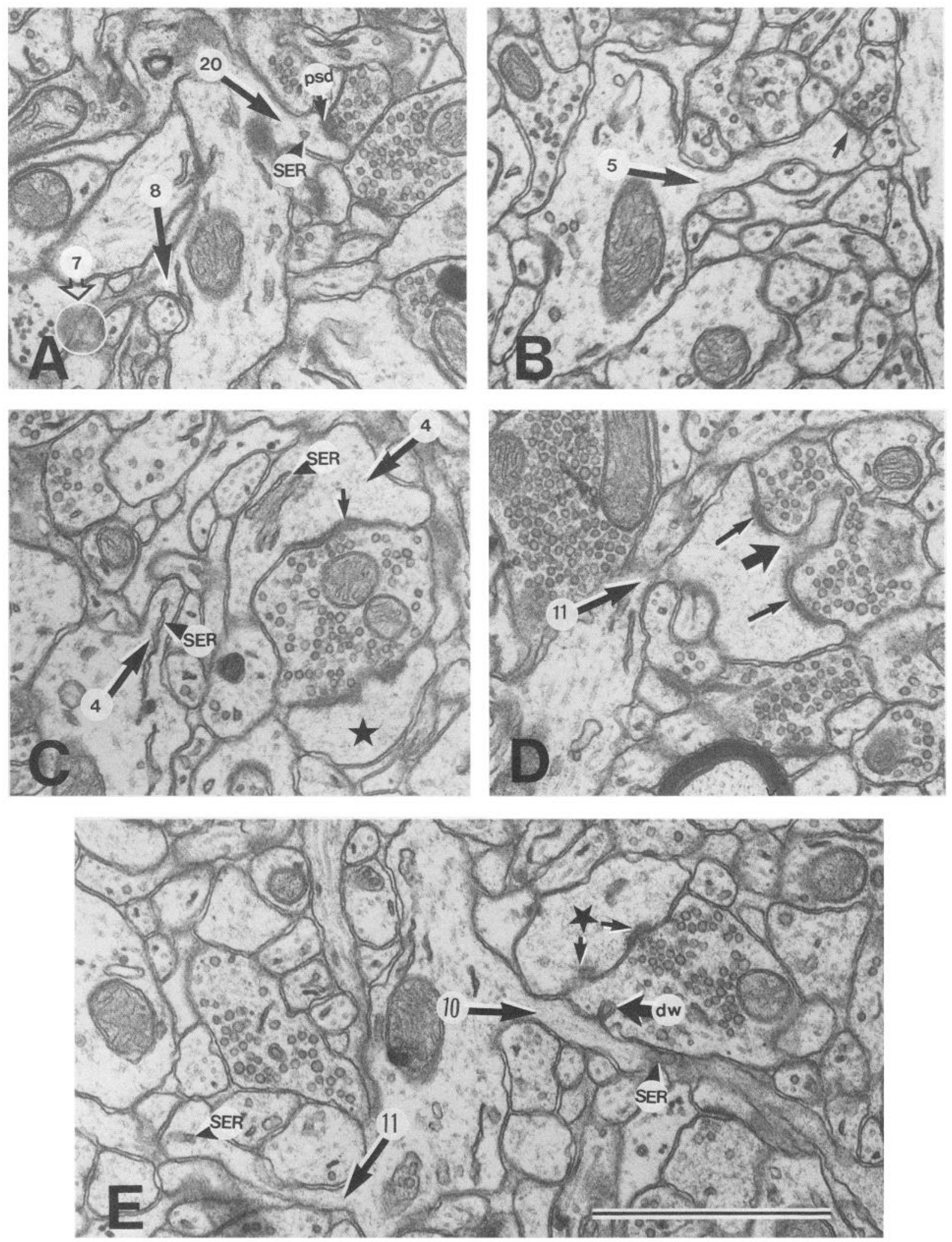

Figure 2. A, Stubby dendritic spine (\#20) from series 21 (arrow). The synaptic PSD and a single cistern of SER are identified. The origin of spine \#8 is indicated, also by an arrow. Also shown (white circle) is the "gray" wall of the head of spine \#7 (open arrow) from the same series. This gray wall overlaps part of the neck of spine 8 , illustrating the difficulty sometimes encountered in identifying the spine surfaces. $B$, Average thin spine $(\# 5)$, also from series 21 , with the PSD indicated by a small arrow. $C$, Spine 4 of series 21 with a small tube of SER in the spine origin that is connected in adjacent sections to the spine apparatus $(S E R)$ of the large head. The synapse is perforated in subsequent sections and has 2 spinules (see the reconstruction in Fig. $3 D$ below). Its axonal varicosity is shared with a similar spine from a different dendrite (star). $D$, Spinule (large arrow) within the perforated synapse (medium arrows) of spine 11 from series 24 . E. Two thin necks of spines \#10 and \#11 from series 21 (see reconstructions in Fig. $3 E$ below). A double-walled $(d w)$ vesicle is present at the neck of spine 10 and is engulfed by a neighboring axon which forms its synapse at a different spine that has a perforated PSD (star). A single cistern of SER is indicated in spine 11 . Calibration bar in $E$ for $A-$ $E$ is $1 \mu \mathrm{m}$. 


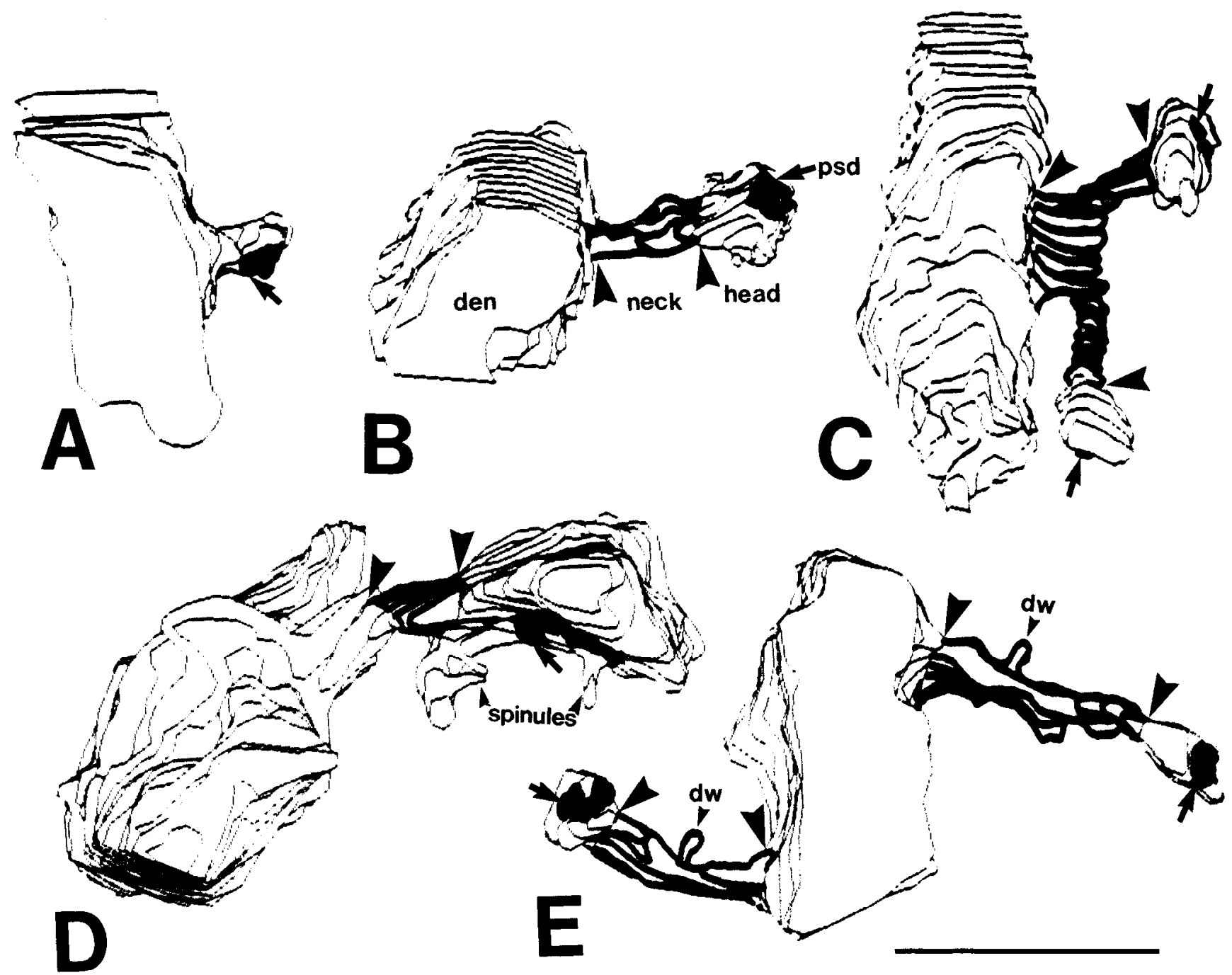

Figure 3. Complete 3-D reconstructions of CA1 dendritic spines, where the dendritic shafts and spine heads are thin gray lines, and the spine necks and synaptic PSDs are thick black lines (filled in for the synapses). A, Stubby spine \#20 of series 21 . B, Average "thin" spine \#5 of series 21 with the dendritic (den), neck, head, and synaptic PSD compartments labeled. The neck compartment occurs between the large arrowheads for $B-$ $E$. $C$, Branched dendritic spine from photographic series 24 with 2 branches, each having average spine dimensions. $D$, Large mushroom spine \#4 of series 21 with 2 spinules between perforations in the synaptic PSD. Only part of the synapse is visible in this viewing angle (small arrow). E, Thin spines 10 and 11 of series 21 , each with double-walled vesicles $(d w)$ on their necks that are engulfed by neighboring nonsynaptic axonal varicosities. Calibration bar in $E$ for $A-E$ is $1 \mu \mathrm{m}$.

\section{SER of dendritic spines}

SER is the only organelle consistently found in hippocampal dendritic spines (Westrum and Blackstad, 1962; Westrum et al., 1980). In some of the smaller CAl dendritic spines, this organelle either was absent or appeared as discontinuous cisternae. This discontinuity may have been caused by insufficient staining or incomplete fixation. The 3 protocols were used in attempts to enhance visualization of the SER. The protocol used for animal 3 seemed to produce the most reliable results, although there were still some spines in series $21,22,24$ that contained discontinuous SER. In most of the larger dendritic spines, the SER was well stained and continuous; however, it usually formed a spine apparatus that had flattened cisternae with highly convoluted contours separated by dense staining material. These were also difficult to reconstruct accurately. It was impossible to discern whether we had a sufficiently accurate reconstruction of the SER in these hippocampal dendritic spincs to perform a quantitative analysis of its volume.

\section{Quantitative evaluation of spine dimensions}

Dimensions of spines, synapses, and axonal varicosities were combined for all 7 dendritic segments and are summarized in Table 2. One hundred unbranched dendritic spines were complete within these photographic series. Of these, 8 were stubby spines with no constriction in their necks, and hence they were treated as spine heads. Thus, 92 spine necks were available for analysis. Fifty-eight varicosities were reconstructed and all of their synaptic vesicles counted (from photographic series 17 , $18,21,22,24)$. The correlation ( $r$ ) between each spine or axonal dimension and the PSD area was determined, and the probability of a significant difference $(p<0.05)$ from zero correlation was tested (Horowitz, 1974). PSD area was positively correlated with total spine volume, although the correlation with spine head volume was much greater than that with spine neck volume (Table 2, Fig. $4 A$ ). The PSD area was correlated with the spine head surfacc arca but not with ncck surface arca. PSD arca was also proportional to the volume of the presynaptic axonal var- 


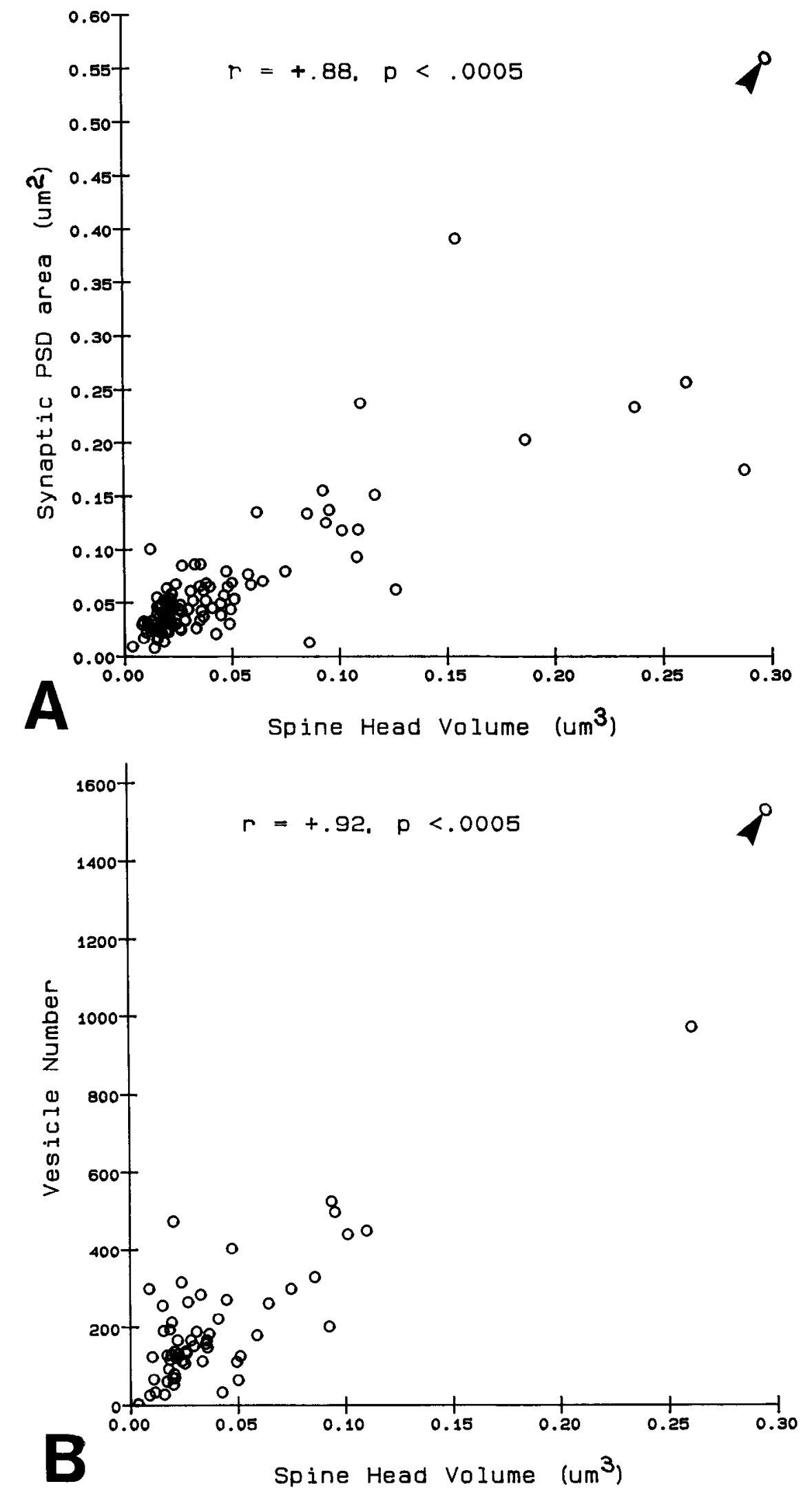

Figure 4. A, Relationship between spine head volume and the area of the PSD. $B$, Relationship between spine head volume and the number of vesicles in the presynaptic axonal varicosity. The volume of the spine at the $a r-$ rowheads in both $A$ and $B$ is $0.55 \mu \mathrm{m}^{3}$. The value $r$ is the correlation between the 2 variables, and $p$ is the probability that $r=0$.

Spine Head Volume $\left(u m^{3}\right)$

icosity and the number of vesicles contained therein. Of the spine length dimensions, PSD area was correlated only with the length of the spine head; it was not correlated with the diameter or length of the spine neck. The total volume of the spine heads and spine necks were correlated $(r=0.30, p<0.005)$; however, the diameter of the spine neck was not correlated with the spine head volume, the total spine length, the spine neck length, or the number of vesicles in the presynaptic axonal varicosity. 
Table 2. Hippocampal CA1 spine dimensions and correlations with synaptic (PSD) area

\begin{tabular}{lrrlll} 
Feature & $N$ & Mean $\pm \mathrm{SD}$ & $\begin{array}{l}\text { Range } \\
\text { (low, high) }\end{array}$ & $r$ & $p$ \\
\hline Synaptic PSD area $\left(\mu \mathrm{m}^{2}\right)$ & 100 & $0.069 \pm 0.08$ & $0.008,0.54$ & - & - \\
Spine volume $\left(\mu \mathrm{m}^{3}\right)$ & 100 & $0.062 \pm 0.08$ & $0.004,0.56$ & +0.88 & $<0.0005$ \\
$\quad$ Head & 100 & $0.051 \pm 0.07$ & $0.003,0.55$ & +0.88 & $<0.0005$ \\
$\quad$ Neck & 92 & $0.012 \pm 0.01$ & $0.0004,0.07$ & +0.32 & $<0.005$ \\
Spine surface area $\left(\mu \mathrm{m}^{2}\right)$ & 100 & $0.83 \pm 0.63$ & $0.13,4.38$ & +0.83 & $<0.0005$ \\
$\quad$ Head & 100 & $0.61 \pm 0.57$ & $0.10,4.24$ & +0.88 & $<0.0005$ \\
Neck & 92 & $0.24 \pm 0.17$ & $0.02,0.89$ & -0.11 & $\mathrm{~ns}$ \\
Axonal varicosity $\left(\mu \mathrm{m}^{3}\right)$ & 58 & $0.11 \pm 0.11$ & $0.005,0.76$ & +0.87 & $<0.0005$ \\
$\quad$ Vesicle number & 58 & $223 \pm 245$ & 3,1606 & +0.90 & $<0.0005$ \\
Spine length $(\mu \mathrm{m})$ & 100 & $0.95 \pm 0.42$ & $0.24,2.46$ & +0.23 & $<0.01$ \\
$\quad$ To PSD & 100 & $0.82 \pm 0.36$ & $0.16,2.13$ & -0.002 & $\mathrm{~ns}$ \\
Head & 100 & $0.53 \pm 0.28$ & $0.15,1.89$ & +0.48 & $<0.0005$ \\
$\quad$ Neck & 92 & $0.45 \pm 0.29$ & $0.08,1.58$ & -0.15 & $\mathrm{~ns}$ \\
Neck diameter $(\mu \mathrm{m})$ & 92 & $0.15 \pm 0.06$ & $0.038,0.46$ & -0.03 & $\mathrm{~ns}$
\end{tabular}

$N$, number of "features" completely contained within these 7 photographic series; $r$, correlation with synaptic PSD area; $p$, probability that $r$ is not different from zero; $\mathrm{ns}, r$ is not significantly different from zero.

"Eight stubby dendritic spines were treated as "heads" because there were no constrictions ("necks") along their lengths.

\section{Axonal varicosities presynaptic to dendritic spines}

Each dendritic spine had only 1 synapse on its head, and most of the presynaptic axonal varicosities of the CA3 afferents (Schaffer collaterals or CA3 commissurals) that formed this spine synapse formed only this one synapse. Spine head volume is well correlated with the volume of the presynaptic axonal varicosity and the number of vesicles contained therein (Fig. $4 B$ ).

Eight of the reconstructed axonal varicosities had more than 1 spine synapsing with them. These spines shared a contiguous population of synaptic vesicles and often differed from one another in shapc. Mushroom and thin spincs (Fig. $5 A$ ), spines with wide or constricted necks (Fig. $5 B$ ), or short and long spines (Fig. $5 C$ ) were seen to share the same presynaptic axonal varicosity. Spines that did not share their presynaptic axonal varicosities were compared to spines that shared their presynaptic axonal varicosities with other dendritic spines (nonsharing and sharing varicosities, respectively, in Table 3 ). There were no significant differences in the dimensions of dendritic spines in these 2 populations. However, there was a significantly greater number of vesicles in the axonal varicosities that were shared by more than one dendritic spine.

\section{Comparison of hippocampal CAI dendritic spine dimensions to cerebellar Purkinje cell dendritic spine dimensions}

Hippocampal series 17, 18 were from the same animal as cerebellar series 20, and hippocampal series $21,22,24$ were from the same animal as cerebellar series 25 . Therefore, the $\mathrm{pH}$ and temperature of the fixative, perfusion times, and processing for electron microscopy were equal. However, fixation quality of the dendrites may not be equivalent in these 2 brain regions because the density of blood vessels in the arachnoid surrounding the Purkinje cell dendrites in the cerebellar folia is much greater than the amount that is found in the hippocampal region. Although membrane structure, microtubule continuity, and mitochondrial integrity were equivalently well preserved in the hippocampus and cerebellum, it is possible that a more rapid perfusion of cerebellum could account for the uniformly con- tinuous SER found in cerebellar dendritic spines. With this caution in mind, a comparison of spine dimensions in the 2 regions is presented in Table 4 .

These comparisons were made within animals. The medians and ranges are presented because the distributions were not normal, thereby precluding parametric testing of differences; and the dispersions were not equal, thereby precluding nonparametric analyses. For both animals, the medians of all cerebellar dendritic spine dimensions and presynaptic axonal dimensions are greater than the medians for all dimensions of hippocampal CA1 spines and their presynaptic axons, although there was some overlap in the ranges. The medians of hippocampal spine dimensions from animal 2 were either greater than or equal to those from animal 3 . There were no consistent differences between animals for the cerebellar dendritic spines.

Table 3. Comparison of spines with nonsharing and sharing axonal varicosities

\begin{tabular}{lccl} 
& $\begin{array}{l}\text { Nonsharing } \\
\text { varicosities } \\
\text { (mean } \pm \mathrm{SD} ; \\
n=48)\end{array}$ & $\begin{array}{l}\text { Sharing } \\
\text { varicosities } \\
\text { (mean } \pm \mathrm{SD} ; \\
n=8)\end{array}$ & \\
Feature & $0.07 \pm 0.08$ & $0.07 \pm 0.08$ & $\mathrm{~ns}$ \\
\hline PSD area $\left(\mu \mathrm{m}^{2}\right)$ & $0.05 \pm 0.08$ & $0.06 \pm 0.09$ & $\mathrm{~ns}$ \\
Spine volume $\left(\mu \mathrm{m}^{3}\right)$ & $0.05 \pm 0.08$ & $0.06 \pm 0.08$ & $\mathrm{~ns}$ \\
Head & $0.007 \pm 0.005$ & $0.007 \pm 0.003$ & $\mathrm{~ns}$ \\
$\quad$ Neck & $0.11 \pm 0.11$ & $0.27 \pm 0.20$ & $<0.001$ \\
Var volume $\left(\mu \mathrm{m}^{3}\right)$ & $217 \pm 243$ & $565 \pm 554$ & $<0.002$ \\
Vesicle number & $0.90 \pm 0.33$ & $0.93 \pm 0.60$ & $\mathrm{~ns}$ \\
Spine length $(\mu \mathrm{m})$ & $0.51 \pm 0.25$ & $0.64 \pm 0.53$ & $\mathrm{~ns}$ \\
Head & $0.39 \pm 0.25$ & $0.34 \pm 0.27$ & $\mathrm{~ns}$ \\
Neck & $0.15 \pm 0.08$ & $0.14 \pm 0.04$ & $\mathrm{~ns}$ \\
Neck diameter $(\mu \mathrm{m})$ & & \\
\hline
\end{tabular}

$\bar{n}$. number of complete varicosities; Var, varicosities; ves, vesicle; $p$, probability that the means of the features are equal for sharing and nonsharing varicosities; ns, means are not significantly different for nonsharing and sharing varicosities. a There were only 46 spine neck measures for nonsharing varicosities because 2 spines were stubby and were treated as spine "heads." For the sharing varicosities, there was 1 stubby spine and thus only 7 spine neck measures. 

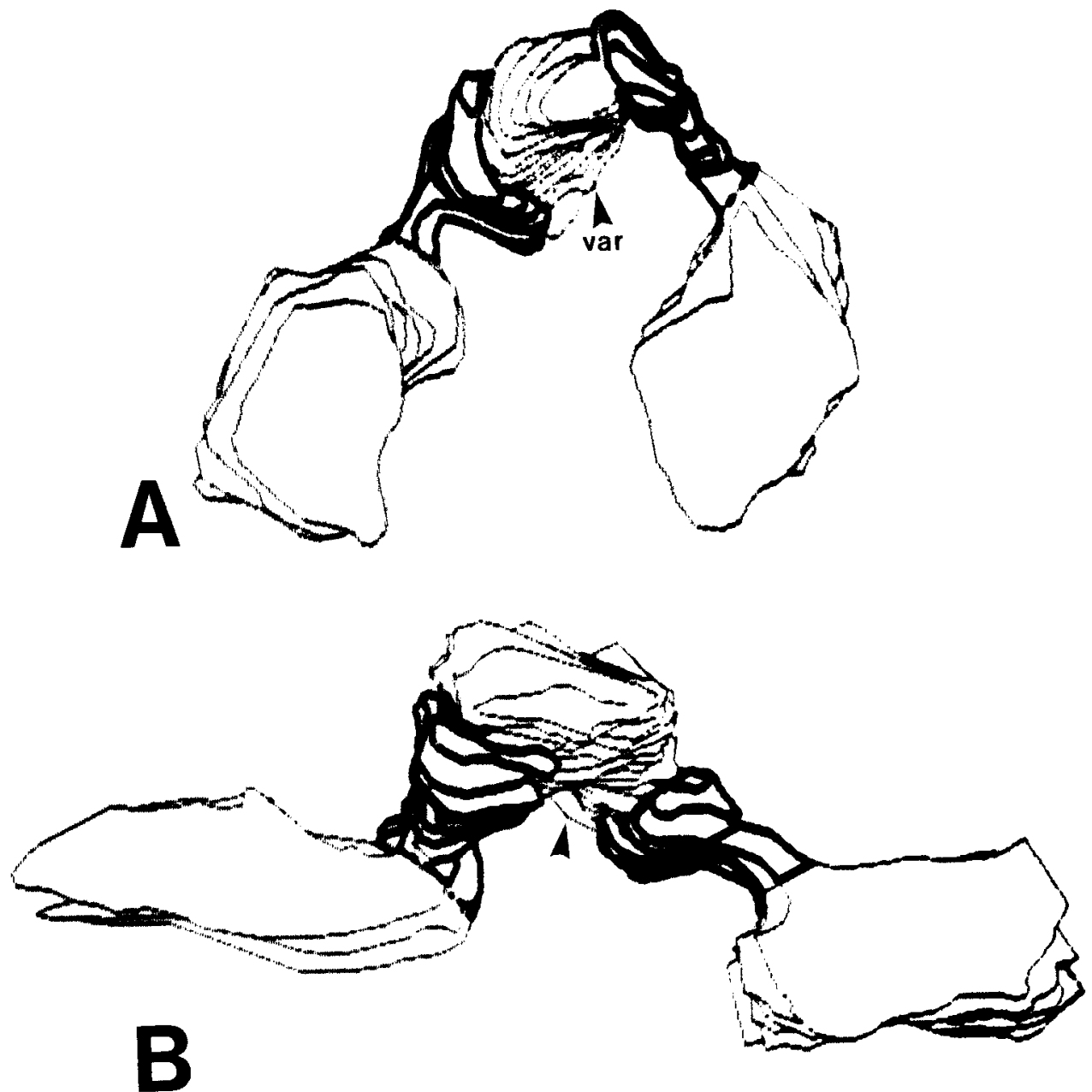

Figure 5. $A-C$, Sharing of a contiguous population of vesicles in presynaptic axonal varicosities (var, arrowheads) by synapses on spines of different dendrites. Calibration bar in $C$ for $A-$ $C$ is $1 \mu \mathrm{m}$.

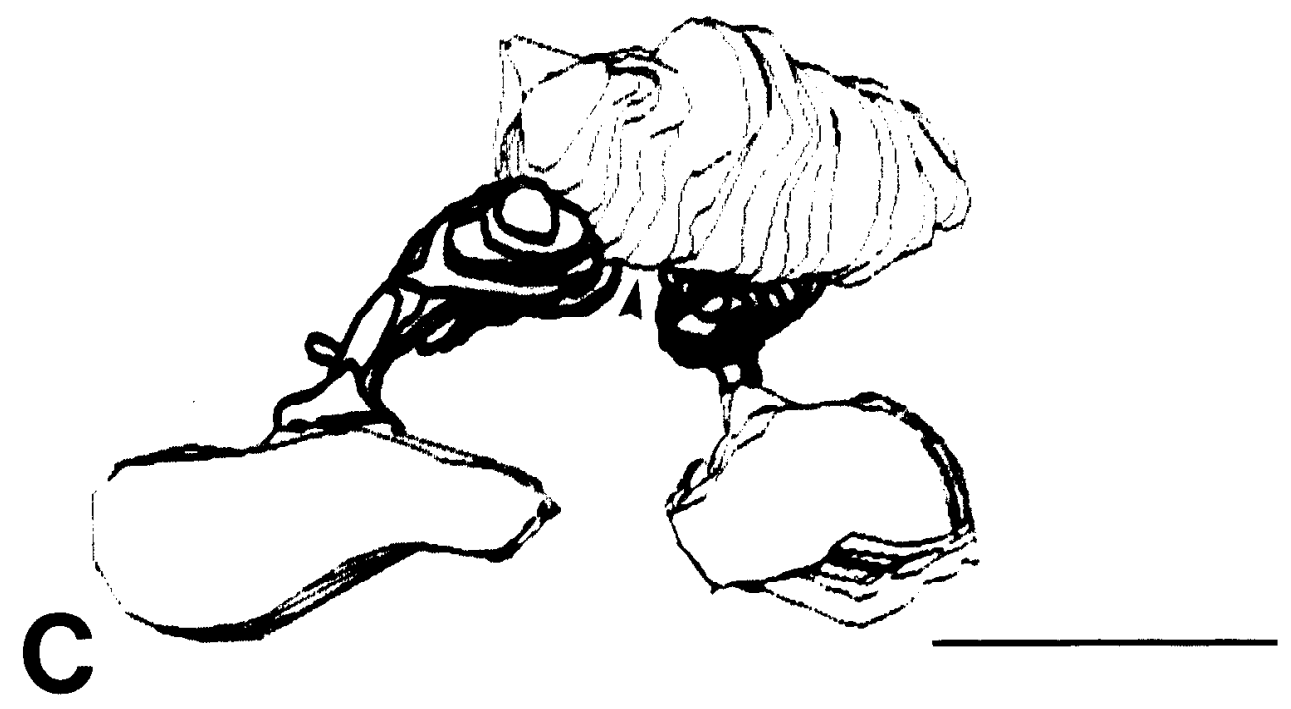

Implications of spine dimensions for the resistance hypothesis

Biophysical models that simulate the transfer of synaptic charge from spine heads through their necks to the recipient dendrites assume the spine heads to be spherical and the spine necks to be cylindrical. The measured head surface areas of these hippocampal spines deviated from predictions based on spherical assumptions by $3.4 \pm 15 \%$ (Fig. $6 \mathrm{~A}$ ). Most of this deviation occurred in the large heads of "mushroom" spines that had perforated synapses whose spinules produced an increased surface area-to-volume ratio. The measured neck surface areas of these reconstructed spines deviated from predictions based on cylindrical assumptions by $-4 \pm 21 \%$ (Fig. $6 B$ ). A 2-sample signed rank test revealed that these deviations were not significant but warned that there are insufficient data to test accurately whether these percentage differences are indeed significant. We 


\begin{tabular}{|c|c|c|c|c|}
\hline \multirow[b]{2}{*}{ Featurc } & \multicolumn{2}{|c|}{$\begin{array}{l}\text { Animal 2, medians } \\
\text { (ranges) }\end{array}$} & \multicolumn{2}{|c|}{$\begin{array}{l}\text { Animal 3, medians } \\
\text { (ranges) }\end{array}$} \\
\hline & $\mathrm{CA} 1(n=27)$ & $\operatorname{Ccrcb}(n=25)$ & $\mathrm{CA} 1(n=43)$ & Cereb $(n=39)$ \\
\hline Synaptic PSD area $\left(\mu \mathrm{m}^{2}\right)$ & $\begin{array}{c}0.061 \\
(0.013-0.24)\end{array}$ & $\begin{array}{c}0.084 \\
(0.039-0.36)\end{array}$ & $\begin{array}{c}0.039 \\
(0.009-0.54)\end{array}$ & $\begin{array}{c}0.145 \\
(0.065-0.35)\end{array}$ \\
\hline Spine volume $\left(\mu \mathrm{m}^{3}\right)$ & $\begin{array}{c}0.037 \\
(0.019-0.14)\end{array}$ & $\begin{array}{c}0.11 \\
(0.059-0.14)\end{array}$ & $\begin{array}{c}0.032 \\
(0.004-0.56)\end{array}$ & $\begin{array}{c}0.13 \\
(0.062-0.18)\end{array}$ \\
\hline Head & $\begin{array}{c}0.036 \\
(0.013-0.13)\end{array}$ & $\begin{array}{c}0.087 \\
(0.042-0.12)\end{array}$ & $\begin{array}{c}0.024 \\
(0.003-0.55)\end{array}$ & $\begin{array}{c}0.11 \\
(0.054-0.17)\end{array}$ \\
\hline Neck & $\begin{array}{c}0.008 \\
(0.001-0.04)\end{array}$ & $\begin{array}{c}0.018 \\
(0.007-0.09)\end{array}$ & $\begin{array}{c}0.006 \\
(0.0004-0.02)\end{array}$ & $\begin{array}{c}0.015 \\
(0.002-0.03)\end{array}$ \\
\hline Spine surface area $\left(\mu \mathrm{m}^{2}\right)$ & $\begin{array}{c}0.72 \\
(0.33-1.50)\end{array}$ & $\begin{array}{c}1.17 \\
(0.77-1.62)\end{array}$ & $\begin{array}{l}0.57 \\
(0.13-4.38)\end{array}$ & $\begin{array}{c}1.17 \\
(0.69-1.52)\end{array}$ \\
\hline Head & $\begin{array}{c}0.57 \\
(0.21-1.26)\end{array}$ & $\begin{array}{l}0.89 \\
(0.47-1.11)\end{array}$ & $\begin{array}{c}0.37 \\
(0.11-4.24)\end{array}$ & $\begin{array}{c}0.95 \\
(0.57-1.25)\end{array}$ \\
\hline Neck & $\begin{array}{c}0.17 \\
(0.040-0.42)\end{array}$ & $\begin{array}{c}0.29 \\
(0.13-1.16)\end{array}$ & $\begin{array}{c}0.13 \\
(0.021-0.56)\end{array}$ & $\begin{array}{c}0.24 \\
(0.054-0.44)\end{array}$ \\
\hline Axonal varicosity $\left(\mu \mathrm{m}^{3}\right)$ & $\begin{array}{c}0.11 \\
(0.039-0.26)\end{array}$ & $\begin{array}{c}0.24 \\
(0.038-0.60)\end{array}$ & $\begin{array}{c}0.11 \\
(0.005-0.76)\end{array}$ & $\begin{array}{c}0.20 \\
(0.050-0.55)\end{array}$ \\
\hline Vesicle number & $\begin{array}{l}196 \\
\quad(70-524)\end{array}$ & $\begin{array}{l}373 \\
\quad(38-821)\end{array}$ & $\begin{array}{l}159 \\
\quad(3-1895)\end{array}$ & $\begin{array}{l}551 \\
(187-1234)\end{array}$ \\
\hline Spine length $(\mu \mathrm{m})$ & $\begin{array}{c}0.92 \\
(0.36-2.19)\end{array}$ & $\begin{array}{c}1.22 \\
(0.91-2.61)\end{array}$ & $\begin{array}{c}0.78 \\
(0.25-2.14)\end{array}$ & $\begin{array}{c}1.17 \\
(0.72-1.69)\end{array}$ \\
\hline Head & $\begin{array}{c}0.52 \\
(0.27-1.39)\end{array}$ & $\begin{array}{c}0.55 \\
(0.43-0.608)\end{array}$ & $\begin{array}{c}0.42 \\
(0.22-1.89)\end{array}$ & $\begin{array}{c}0.59 \\
(0.47-0.68)\end{array}$ \\
\hline Neck & $\begin{array}{c}0.30 \\
(0.09-1.67)\end{array}$ & $\begin{array}{c}0.68 \\
(0.37-2.18)\end{array}$ & $\begin{array}{c}0.32 \\
(0.08-1.06)\end{array}$ & $\begin{array}{c}0.59 \\
(0.12-1.11)\end{array}$ \\
\hline Neck diameter $(\mu \mathrm{m})$ & $\begin{array}{c}0.16 \\
(0.08-0.46)\end{array}$ & $\begin{array}{c}0.20 \\
(0.13-0.28)\end{array}$ & $\begin{array}{c}0.12 \\
(0.04-0.26)\end{array}$ & $\begin{array}{c}0.19 \\
(0.10-0.27)\end{array}$ \\
\hline
\end{tabular}

CAl, dendritic spines from hippocampal CAl pyramidal cells; Cereb, dendritic spines from cerebellar Purkinje spine branchlets (Harris and Stevens, 1988b); other abbreviations as in Table 1.

assume for subsequent discussion, however, that the deviations from sphcrical and cylindrical are within the range $(<5 \%$ on average) of experimental measurement error.

We used Wilson's simulation software (1984) to test whether the dimensions of these hippocampal spine necks might reduce the amount of synaptic charge reaching the recipient dendrite from the theoretical maximum that would be possible if the synapse had occurred directly on the dendritic shaft (Belmont and Harris, unpublished observations). Spine membrane resistivity was set at $2000 \Omega-\mathrm{cm}^{2}$, and cytoplasmic resistivity was set at $100 \Omega-\mathrm{cm}$. With these membrane and cytoplasmic resistivities, the axial resistance of the measured hippocampal spine necks would be $0.90-411 \mathrm{M} \Omega$, and the axial conductance would be $2-1108 \mathrm{nS}$ (Fig. 7). For the measured cerebellar dendritic spines, axial resistance of the spine neck would be $2.6-80 \mathrm{M} \Omega$, and the axial conductance would be $12-383 \mathrm{nS}$ (Fig. 7). The alpha function was set at 50 and simulated a transient synaptic conductance change that reached a peak value of $1 \mathrm{nS}$ or $5 \mathrm{nS}$ (for a detailed discussion of the alpha function, see Wilson, 1984, and Brown et al., 1988). A transient synaptic conductance that reaches only $1 \mathrm{nS}$ is thought to be closer to the true physiological value for hippocampal neurons from in vitro slices (Brown et al., 1988; D. Johnston, personal communication) and for cultured hippocampal neurons (Bekkers and Stevens, 1988).

Multiple curves like those published in figure $7 a$ of Wilson (1984) were used to determine the intersection of neck diameters and lengths that would cause $5,10,20,30$, and $40 \%$ reduction in pcak synaptic current (Bclmont and Harris, unpublished observations). The measured neck dimensions for hippocampal and cerebellar dendritic spines were then superimposed on these theoretical curves for $1 \mathrm{nS}$ peak conductance (Fig. $8 A$ ) and $5 \mathrm{nS}$ peak conductance (Fig. $8 B$ ). If peak synaptic conductance were only $1 \mathrm{nS}$, then 1 hippocampal and 0 cerebellar spine necks would reduce charge transfer by more than $10 \%$ (Table 5). If peak synaptic conductance were $5 \mathrm{nS}$, then 30 hippocampal and 24 cerebellar spine necks would reduce charge transfer by more than $10 \%$ (Table 5).

Table 5. Number of dendritic spines below or at each percentage reduction in Figure 8, $A, B$

\begin{tabular}{llllllll}
\multirow{2}{*}{$\begin{array}{l}\text { Gmax } \\
\text { (nS) }\end{array}$} & Region & \multicolumn{7}{l}{ Percentage reductions } \\
\cline { 3 - 8 }$>40 \%$ & $<40 \%$ & $<30 \%$ & $<20 \%$ & $<10 \%$ & $<5 \%$ \\
\hline 1 & CA1 & 0 & 0 & 1 & 0 & 10 & 81 \\
1 & Cereb & 0 & 0 & 0 & 0 & 2 & 62 \\
5 & CA1 & 1 & 0 & 10 & 19 & 25 & 37 \\
5 & Cereb & 0 & 0 & 1 & 23 & 27 & 13
\end{tabular}

Abbreviations: Gmax, peak synaptic conductance in $\mathrm{nS}$; CAl, hippocampal dendritic spines from area CAl pyramidal cells; Cereb, cerebellar dendritic spines from Purkinje spine branchlets. 


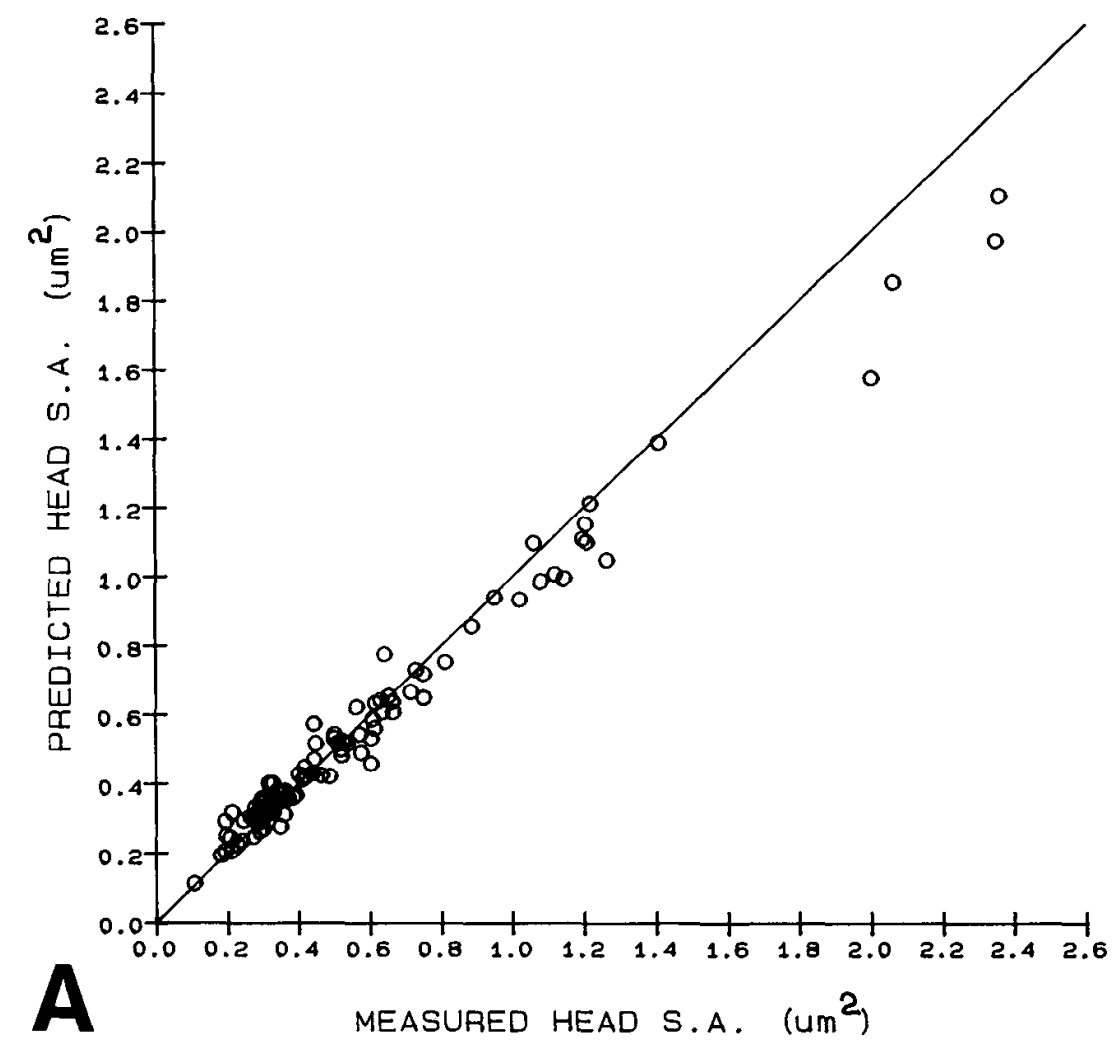

Figure 6. A, Predicted surface area of spine heads if they were assumed to be spherical compared to the surface area that was measured through serial sections. $B$, Predicted surface area of spine necks if they were assumed to be cylindrical compared to the measured neck surface area. In both $A$ and $B$ the line indicates where predicted and measured values are the same.

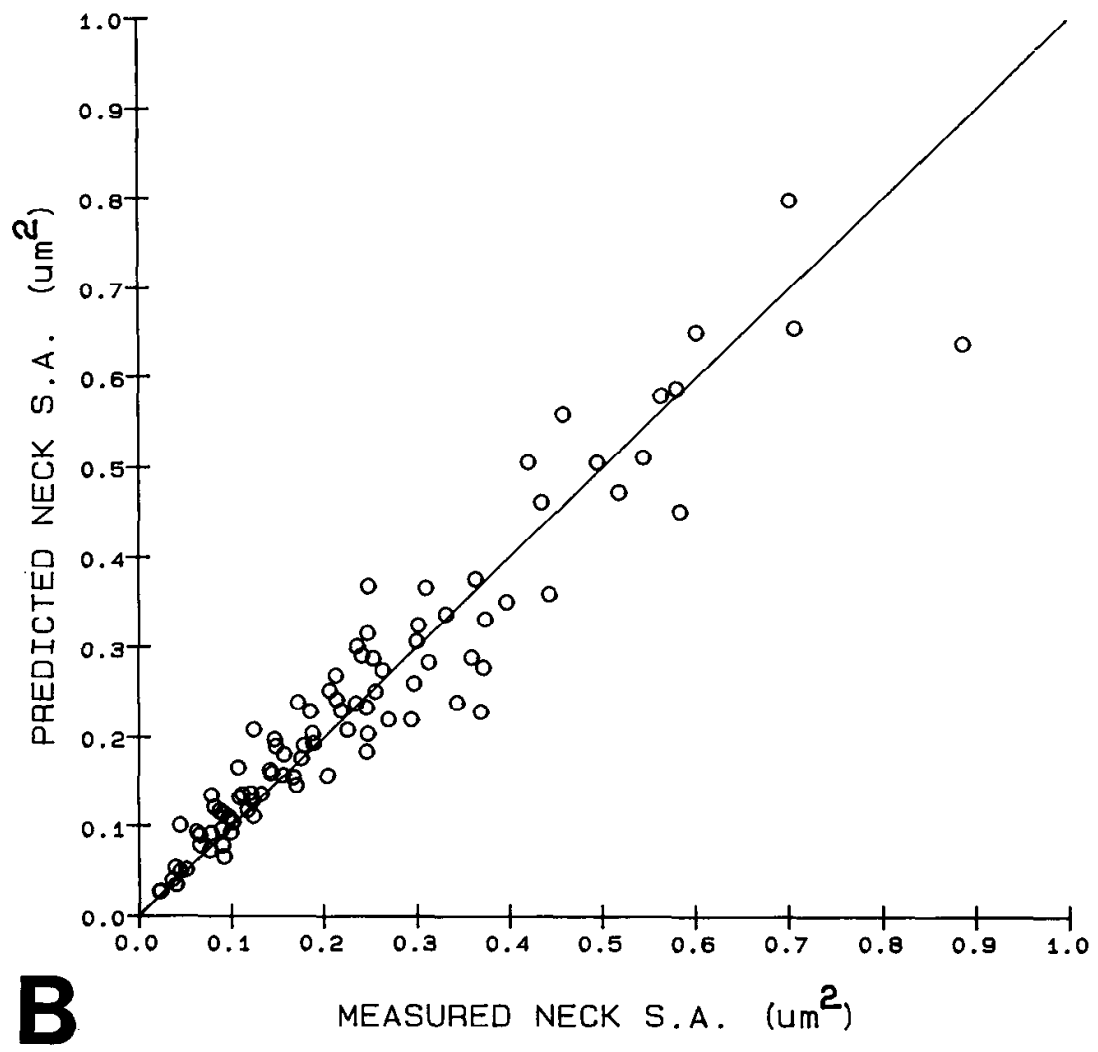




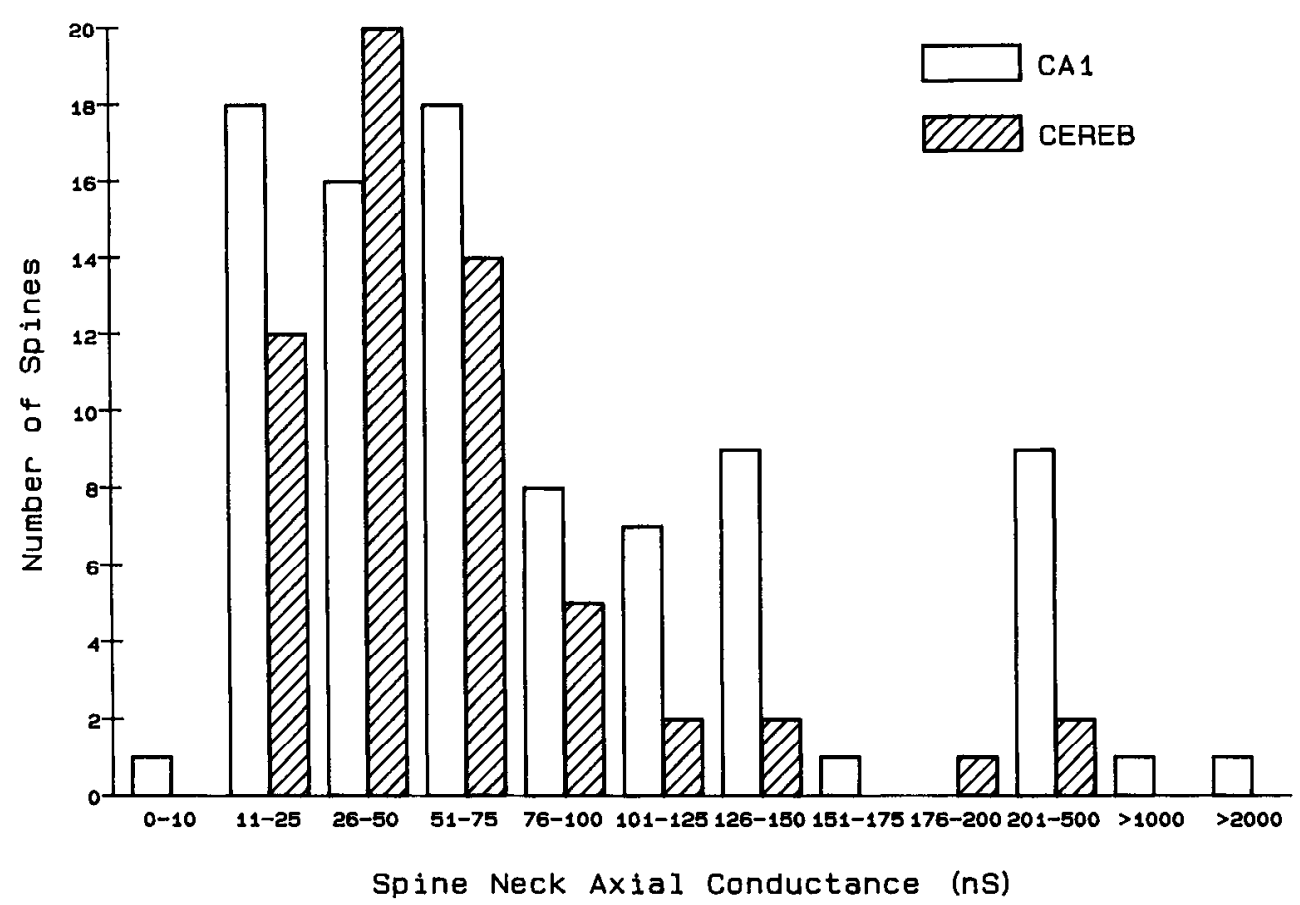

Figure 7. Axial conductances in the measured hippocampal CA1 and cerebellar spine necks assuming the specific cytoplasmic resistance to be 100 $\Omega$-cm.

\section{Discussion}

These results show that the density of spines along reconstructed CAl pyramidal cell dendrites is in the range of that measured from light microscopy of Golgi impregnated dendrites, and that spines of diverse shapes are neighbors (Wenzel et al., 1973; Minkwitz, 1976; Frotscher et al., 1978; Haschke et al., 1980; and Harris and Stevens, 1988a). Spine head dimensions, but not neck dimensions, are proportional to the area of the PSD and to the number of vesicles in the presynaptic axonal varicosity. A few axonal varicosities share a contiguous population of vesicles between 2 spines from different dendritic segments. These "sharing" varicosities contained more vesicles than "nonsharing" varicosities, suggesting that they might be compensating for serving more than one synaptic junction. Some hippocampal spines are branched, and all the spine branches form synaptic junctions with axonal varicosities containing vesicles. All dimensions of most of the hippocampal dendritic spines are smaller than those of most of the cerebellar dendritic spines from the same animals. The relationship between hippocampal and cerebellar spine head volume and surface area, and between spine neck volume and surface area deviates only slightly from spherical and cylindrical; therefore, we could use a biophysical model of passive dendritic spines to determine the effect that spine neck dimensions might have on charge transfer to their recipient dendrite (Wilson, 1984; Belmont and Harris, unpublished observations).

\section{Spine sample selection}

The detailed description of spines from 7 dendritic segments in hippocampal area $\mathrm{CA} 1$ of 3 rats seemingly represents a small sample of the large population of dendritic spines located there. All 3 rats were sexually mature adults, but they were of different weights and ages and were subjected to different staining protocols to optimize for visualization of the SER. All the dendritic series showed excellent quality of fixation as judged by continuous plasmalemmae, unswollen mitochondria, continuous mi- crotubules, and complete synapses; however, the SER was discontinuous in some spines, possibly reflecting incomplete fixation or staining.

It was impossible to determine whether the tissue processing itself could have altered spine shape. In a subsequent study, we have compared mitochondrial cross-sectional areas from this tissue and hippocampal slices prepared by rapid immersion fixation in $6 \%$ glutaraldehyde for $8 \mathrm{sec}$ with microwave irradiation and then processed by these same staining procedures (Jensen and Harris, 1988). Within both groups, isolated dendrites that had large mitochondria could be found, but these might have reflected "real" differences in prefixation physiological states. This mitochondrial comparison revealed no significant differences, suggesting that generalized swelling or shrinkage could not be correlated with the concentration of aldehydes in the fixative. We have also observed hippocampal dendrites from cultures maintained in vitro with video-enhanced contrast microscopy at high magnifications (greater than 2000 $x$ ). We were unable to detect any measurable change in dendritic or spine dimensions before, during, or for $1 \mathrm{hr}$ after immersion in fixative containing the aldehyde concentrations used here $(\mathrm{K}$. M. Harris, unpublished observations). Hence, in the absence of specific evidence at the ultrastructural level for fixation-induced swelling or shrinkage of dendrites and spines, no "correction" factor has been introduced to account for this potential artifact.

These CAl dendritic segments provided an unbiased sampling of dendritic spines, because at the time when the dendrites were chosen for photography in the middle sections of the series, we could not know any of the spine properties that would occur in preceding or subsequent sections. The range of PSD areas on these reconstructed spines completely overlapped the range of a larger population of PSDs on other spines in stratum radiatum, thus supporting the assertion that the reconstructed spines are not unique among CAl dendrites, but probably represent a larger population of spines found there (Harris et al., 1987, 1988). The observations that average CAl spine dimensions were larger in animal 2 than in animal 3 are consistent with our 

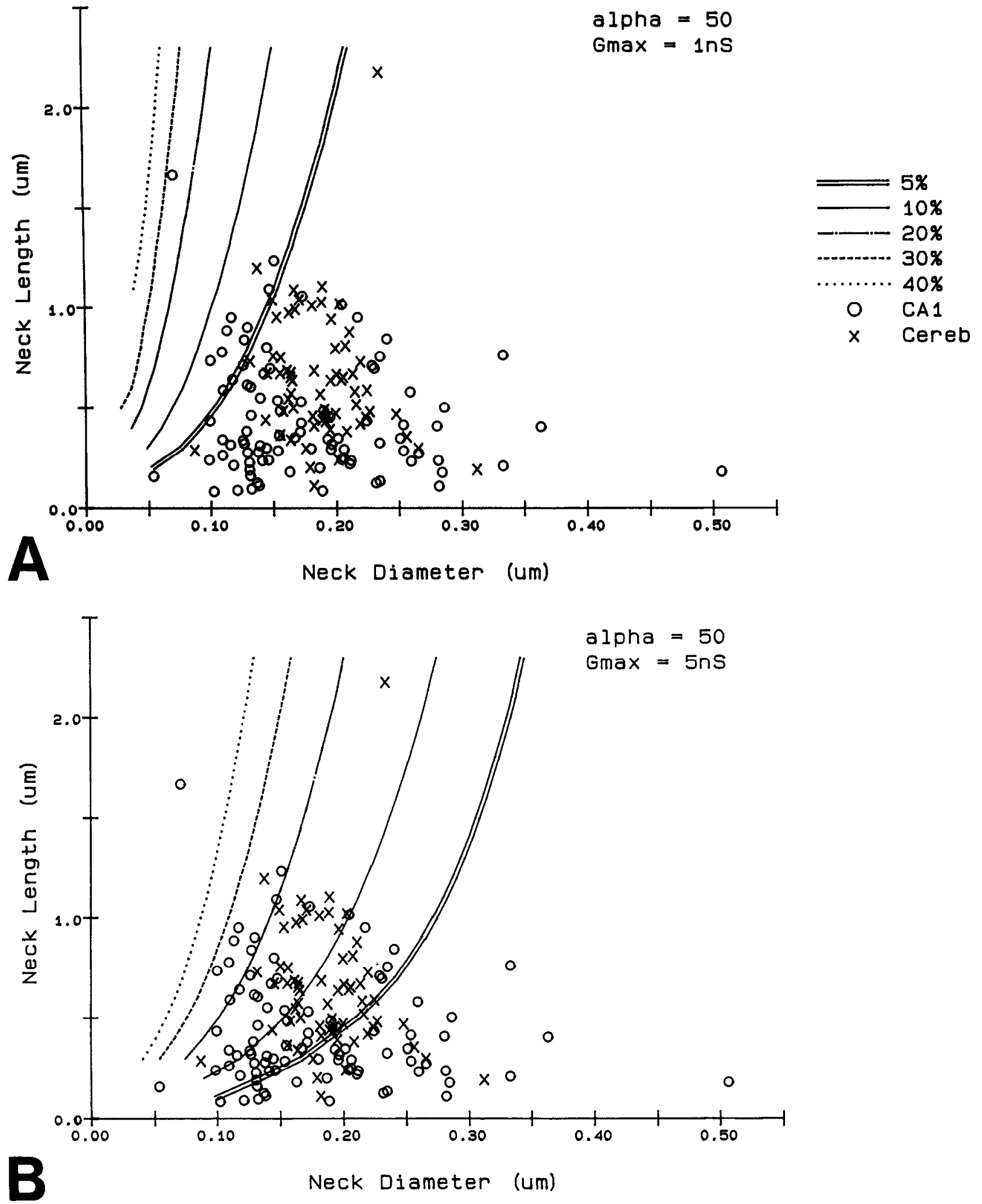

Figure 8. Theoretical percentage reduction (range $=5-40 \%$ ) from maximal charge transfer that would occur if a synapse occurs directly on the dendritic shaft instead of on a dendritic spine. $A$, Percentage reduction for a peak synaptic conductance $(G m a x)$ of $1 \mathrm{nS}$. $B$, Percentage reduction for a peak synaptic conductance of $5 \mathrm{nS}$. For both simulations, alpha was 50 and the measured spine neck dimensions for all of the hippocampal CA1 (circles) and cerebellar $(x)$ spines were superimposed on the theoretical curves. 
findings in developing animals that more large dendritic spines are found in younger animals (Harris et al., 1987, 1988).

\section{Evidence for spine remodeling}

The presence of branched spines, spinules on spine heads, and double-walled vesicles engulfing portions of the spine necks suggests that they are normal features of the adult hippocampal neuropil and might represent ongoing plasticity or growth and differentiation of these spines. It seems unlikely, however, that the hippocampal branched spines represent the splitting of previously single spines, because the heads of branched spines are widely separated in the neuropil and their synapses do not share the same presynaptic axonal varicosity (Neito-Sampedro et al., 1982).

\section{Relationships between hippocampal spine geometry and anatomical indicators of synaptic efficacy}

We use the phrase "synaptic efficacy" in its broadest interpretation to include the constellation of events that begins with presynaptic availability and release of neurotransmitter, response of postsynaptic receptors, effect of spine geometry on charge transfer, and response of the postsynaptic cell. We assume that enhancing any subset of these events or their molecular components would lead to enhanced synaptic efficacy, and vice versa for decrement in synaptic efficacy. Larger CA1 spine heads are associated with larger synapses and more vesicles in the presynaptic axonal varicosity. We assume that larger PSDs and more synaptic vesicles reflect greater synaptic efficacy. This assumption seems reasonable for CA1 synapses for at least 2 reasons. First, the density of intramembranous particles at CAl synapses does not change with the size of the PSD when viewed in freeze-fracture preparations; therefore, the larger synaptic PSDs are likely to contain more receptors or other proteins associated with synaptic transmission (Harris and Landis, 1986). Second, with paired pulse stimulation of voltage-clamped CA1 cells in culture, the second response increases linearly relative to the first (Bekkers and Stevens, 1988). This linear increase in response suggests that the receptors are not saturated by the first impulse, and therefore not by a single quantal ("vesicular") release. Thus, we propose that hippocampal spine head size might be directly responsive to shifts in synaptic efficacy as indicated by differences in the PSD area and the number of vesicles in the presynaptic axonal varicosity. The areas of PSDs on neostriatal (Wilson et al., 1983), cortical (Spacek and Hartmann, 1983), and cerebellar dendritic spines (Harris and Stevens, $1988 \mathrm{a}, \mathrm{b}$ ) are also proportional to the total spine surface arcas and occupy only about $10 \%$ of the available spinc surfacc. Thus, the spine synapses require more volume and surface area than that associated with the PSD.

In contrast to the dimensions of hippocampal and cerebellar spine heads, the spine neck dimensions are not proportional to PSD area or the number of vesicles in the axonal varicosity. Neostriatal (Wilson et al., 1983) and cortical (Spacek and Hartmann, 1983) spine neck dimensions are also not proportional to the PSD area. These findings suggest that the dimensions of hippocampal dendritic spine necks might not be modified directly to mediate shifts in synaptic efficacy. They further show that both long and short spines can have relatively thin or thick necks with large or small heads and synapses.

A complete quantification of SER volume was impossible for some of these hippocampal dendritic spines; however, most large hippocampal spines have more SER than small ones (Har- ris and Stevens, 1988a). Therefore, hippocampal spine size may also be proportional to the volume of SER and may be controlled by the volume required to house this organelle, as previously suggested for cerebellar dendritic spines, dendritic varicosities from several cell types, and nonsynaptic axonal varicosities (Sasaki-Sherrington et al., 1984; Jacobs and Stevens, 1986a, b; Harris and Stevens, 1988b; Stevens et al., 1988). Wilson (1984) also reported difficulty in reconstructing the delicate portions of the spine apparatus in striatal spines, but recognized that larger striatal spines also had larger spine apparatuses and suggested that spine size and shape might be controlled by an interaction between the apparatus and the cytoskeletal network.

\section{Influence of spine neck geometry on resistance to synaptic transmission and implications for physiological plasticity}

Many biophysical models have suggested that changes in spine neck dimensions could modulate synaptic efficacy under certain conditions (Chang, 1952; Diamond et al., 1970; Rall, 1970, 1974, 1978; Perkel, 1982-1983; Koch and Poggio, 1983; Kawato et al., 1984; Turner, 1984; Wilson, 1984; Perkel and Perkel, 1985). For mathematical purposes, these models have assumed the spine head to be spherical and the spine neck to be cylindrical. Our empirical measurements support these assumptions for $\mathrm{CAl}$ and cerebellar dendritic spines. The plasma membrane resistance and cytoplasmic resistance of the dendritic spines have been assumed to fall within the range measured from cell somas and dendrites because direct physiological measurement of intrinsic spine characteristics has been impossible. Measurement of synaptic conductances that occur at individual spine synapses has also been impossible, though biophysical models show that the effect that spine dimensions have on total charge transfer is related nonlinearly to the magnitude of conductance changes that occur at the synapses (e.g., Koch and Poggio, 1983; Wilson, 1984).

Our application of Wilson's simulation software to these hippocampal and cerebellar dendritic spines must be considered a preliminary strategy to test whether their dimensions are likely to modify the amount of synaptic charge reaching the recipient dendrite. If the theoretical predictions are correct, then we conclude, like Wilson (1984) and Brown et al. (1988), that the effect of spine neck dimensions on charge transfer is critically dependent on the magnitude of conductance change occurring at the synapse. Further analysis is in progress to determine the range in the intrinsic biophysical characteristics (e.g., $\mathrm{Rm}$ of the spine membrane and $\mathrm{Ri}$ of the spine cytoplasm) that might effect charge transfer in these measured spines (Belmont and Harris, unpublished observations). Brown et al. (1988) simulated higher values for $\mathrm{Rm}$ and $\mathrm{Ri}$ and found that these variations had "no qualitative effect" on the inference that synaptic conductance is the single most critical factor in determining the effect of spine geometry on charge transfer.

Repeated activation of CA3 afferents that synapse on dendritic spines in stratum radiatum of area CA1 results in longlerm potentiation (LTP) of the physiological response. Results from anatomical studies throughout all hippocampal subregions suggest that hippocampal spines swell and shorten, heads become rounded or, conversely, more concave, and PSD area increases with induction of LTP (Van Harreveld and Fifkova, 1975; Moshkov, 1977, 1980; Fifkova and Anderson, 1981; Lee et al., 1981; Desmond and Levy, 1983, 1988; Chang and Greenough, 1984; Wenzel et al., 1985; Petukhov and Popov, 1986; Andersen et al., 1988a, b; Harris et al., 1988a for review). Other 
hippocampal studies that employed serial electron microscopy to evaluate spine shape suggest that short and stubby spines can mediate LTP and that spine neck shortening and widening might not be necessary for LTP (Reeves and Steward, 1986; Harris et al., 1987, 1988). The biophysical results presented here suggest that if LTP induces a synaptic conductance approaching $5 \mathrm{nS}$, then widening and shortening of $30 \%$ of the spines could further enhance charge transfer by more than $10 \%$. However, if synaptic conductance following LTP is less than $5 \mathrm{nS}$, then the same alterations in spine geometry would have little further effect on charge transfer to the recipient dendrite.

If instead spine neck constriction serves to prevent diffusion of biochemical products of LTP away from activated synapses, then LTP might be restricted specifically to those spines that were synapsing with the activated axons (Brown et al., 1988; Harris and Stevens, 1988a). Only the size of the hippocampal spine heads fluctuates across spines of differing morphologies in proportion with other anatomical indicators of synaptic efficacy. If compartmentation is an important function of hippocampal dendritic spines, as was suggested for cerebellar dendritic spines, then changes in synaptic efficacy might alter the dimensions of the spine heads that are holding the activated molecules. Complete reconstructions and biophysical modeling of activated dendritic spines will be necessary to resolve whether hippocampal spine necks constrict or widen to change resistance to charge transfer or to restrict diffusion of activated molecules away from potentiated synapses.

\section{References}

Andersen, P., T. Blackstad, G. Hulleberg, J. Line Vaaland, and M. Trommald (1988a) Changes in spine morphology associated with long-term potentiation in rat dentate granule cells. Proc. Physiol. Soc. S. 3.

Andersen, P., T. Blackstad, G. Hulleberg, M. Trommald, and J. L. Vaaland (1988b) Dimensions of dendritic spines of rat dentate granule cells during long-term potentiation (LTP). Proc. Physiol. Soc. P.C. 50 .

Bekkers, J. M., and C. F. Stevens (1988) Dual models of excitatory synaptic transmission in the brain. Proc. NIMH Conference of Molecular Neurobiology, Government Printing Otfice, Washington, D.C. (in press).

Brown, T. H., V. C. Chang, A. H. Ganong, C. L. Keenan, and S. R. Kelso (1988) Biophysical properties of dendrites and spines that may control the induction and expression of long-term synaptic potentiation. Neurol. Neurobiol. 35:201-264

Chang, F. L. F., and W. T. Greenough (1984) Transient and enduring morphological correlates of synaptic activity and efficacy in the rat hippocampal slice. Brain Res. 309: 35-46.

Chang, H. T. (1952) Cortical neurons with particular reference to the apical dendrites. Cold Spring Harbor Symp. Quant. Biol. 17: 189202.

Coss, R. G., and D. H. Perkel (1985) The function of dendritic spinesA review of theoretical issues. Behav. Neural Biol. 44: 151-185.

Crick, F. (1982) Do dendritic spines twitch? Trends Neurosci. 5: 4446.

Desmond, N. L., and W. B. Levy (1983) Synaptic correlates of associative potentiation/depression: an ultrastructural study in the hippocampus. Brain Res. 265: 21-30.

Desmond, N. L., and W. B. Levy (1988) Anatomy of associative longterm synaptic modification. Neurol. Neurobiol. 35: 201-264.

Diamond, J., E. G. Gray, and G. M. Yasargil (1970) The function of dendritic spines: An hypothesis. In Excitatory Synaptic Mechanisms, P. Andersen and J. Jensen, eds., pp. 213-222, Universitets Forlaget, Oslo.

Frotscher, M., K. Scharmacher, and M. Scharmacher (1978) Zur umwetabhangigen differenzierung von pyramidenneuronen im hippocampus (CA1) der ratte die differenzierung von apikalen seitendendriten und basaldendriten. J. Hirnforsch. 19: 445-456.

Gamble, E., and C. Koch (1987) The dynamics of free calcium in dendritic spines in response to repetitive synaptic input. Science 236: 1311-1315.

Greenough, W. T., and C. Bailey (1988) The anatomy of a memory: Convergence of results across a diversity of tests. Trends Neurosci. 11: $142-147$.

Harris, K. M., and D. M. D. Landis (1986) Synaptic membrane structure in area CA1 of the rat hippocampus. Neuroscience 19:857-872.

Harris, K. M., and J. K. Stevens (1988a) Study of dendritic spines by serial electron microscopy and three-dimensional reconstructions. Neurol. Neurobiol. 37: 179-199.

Harris, K. M., and J. K. Stevens (1988b) Dendritic spines of rat cerebellar Purkinje cells: Serial electron microscopy with reference to thcir biophysical charactcristics. J. Neurosci. 8: 4455-4469.

Harris, K. M., J. Trogadis, and J. K. Stevens (1985) Three dimensional structure of dendritic spines in the rat hippocampus (CA1) and cerebellum. Soc. Neurosci. Abstr. 10: 306.

Harris, K. M., F. E. Jensen, and B. Tsao (1987) Development of hippocampal LTP, synapses, and spines. Soc. Neurosci. Abstr. 13: 394.

Harris, K. M., F. E. Jensen, and B. Tsao (1988) Ultrastructure, development, and plasticity of synapses in area CAl of the rat hippocampus: Extending our vision with serial electron microscopy and three dimensional analyses. Neurol. Neurobiol. (in press).

Haschke, A., W. Mende, and H.-G. Minkwitz (1980) Zur entwicklung von dendritenstrukturen on CAl pyramidenneneuronen des hippocampus der ratte in abhängigkeit ihrer schichten zugehörigkeit mit und ohne unspezifischer experimenteller becinflussung. Z. Mikrok.anat. Forsch. 94: 593-622.

Horowitz, L. M. (1974) Elements of Statistics for Psychology and Education, McGraw-Hill, New York.

Horwitz, B. (1984) Electrophoretic migration due to postsynaptic potential gradients: Theory and application to autonomic ganglion neurons and to dendritic spines. Neuroscience 12: 887-905.

Jacobs, J. R., and J. K. Stevens (1986a) Experimental modification of $\mathrm{PC} 12$ neurite shape with the microtubule-depolymerizing drug Nocodazole. J. Cell Biol. 103: 907 -915.

Jacobs, J. R., and J. K. Stevens (1986b) Changes in the organization of the neuritic cytoskeleton during nerve growth factor activated differentiation of PC12 cells: A serial electron microscopic study of the development and control of neurite shape. J. Cell Biol. 103: 895-906.

Jensen, F. E., and K. M. Harris (1988) Rapid fixation of in vitro brain slices using microwave irradiation. Soc. Neurosci. Abstr. 14: 220.

Kawato, M., T. Hamaguchi, F. Murakami, and N. Tsukahara (1984) Quantitative analysis of electrical properties of dendritic spines. Biol. Cybern. 50: 447-454.

Koch, C., and T. Poggio (1983) A theoretical analysis of electrical properties of spines. Proc. R. Soc. Lond. B 218: 455-477.

Lee, K. S., F. Schottler, M. Oliver, and G. Lynch (1980) Brief bursts of high-frequency stimulation produce two types of structural change in the rat hippocampus. J. Neurophysiol. 44: 247-258.

Meek, G. A. (1976) Practical Electron Microscopy for Biologists, Wiley, New York.

Miller, J. P., W. Rall, and J. Rinzel (1985) Synaptic amplification by active membrane in dendritic spines. Brain Res. 325: 325-330.

Minkwitz, H.-G. (1976) Zur entwicklung der neuronenstruktur des hippocampus wahrend der pra- und postnatalen ontogenese der albinoratte. III. Mittelung: morphometrische erfassung der ontogenetischen veranderungen in dendritenstruktur und spinebesatz an pyramidenneuronen (CA1) des hippocampus. J. Hirnforsch. 17: 255276.

Moshkov, D. A., L. L. Petrovskaia, and A. G. Bragin (1977) Posttetanic changes in the ultrastructure of the giant spinous synapses in hippocampal field CA3. Dokl. Akad. Nauk. USSR 237: 1525-1528.

Moshkov, D. A., L. L. Petrovskaia, and A. G. Bragin (1980) Ultrastructural study of the bases of postsynaptic potentiation in hippocampal sections by the freeze-substitution method. Tsitologiia 22: 20-26.

Neito-Sampedro, M., S. F. Hoff, and C. W. Cotman (1982) Perforated postsynaptic densities: Probable intermediates in synapse turnover. Proc. Natl. Acad. Sci. USA 79: 5718-5722.

Pearlstein, R. A., L. Kirschner, J. Simons, S. Machell, W. F. White, and R. L. Sidman (1986) A multimodal system for reconstruction and quantification of neurologic structures. Anal. Quant. Cytol. Histol. 8 . 108-115.

Perkel, D. H. (1982-1983) Functional role of dendritic spines. Physiologie 78: 695-699. 
Perkel, D. H., and D. J. Perkel (1985) Dendritic spines: role of active membrane in modulating synaptic efficacy. Brain Res. 325: 331-335.

Petukhov, V. V., and V. I. Popov (1986) Quantitative-analysis of ultrastructural-changes in synapses of the rat hippocampal field CA3 in vitro in different functional-states. Neuroscience 18: 823-835.

Rall, W. (1970) Cablc propertics of dendrites and effects of synaptic location. In Excitatory Synaptic Mechanisms, P. Andersen and J. K. S. Jensen, eds., pp. 175-187, Universitets Forlaget, Oslo.

Rall, W. (1974) Dendritic spines, synaptic potency and neuronal plasticity. In Cellular Mechanisms Subserving Changes in Neuronal Activity, C. Woody, K. Brown, T. Crow, and J. Knispel, eds., pp. 1321, Brain Information Service, UCLA, Los Angeles, CA.

Rall, W. (1978) Dendritic spines and synaptic potency. In Studies in Neurophysiology, A. K. McIntyre and K. Porter, eds., pp. 203-209, Cambridge U. P., Cambridge.

Rall, W., and I. Segev (1988) Synaptic integration and excitable dendritic spine clusters: Structure/function. Neurol. Neurobiol. 37: 263282.

Ramón y Cajal, S. (1891) Sur la structure de l'écorce cérébrale de quclques mammifercs. Cellule $7:$ 124-176.

Ramón y Cajal, S. (1911) Histologie du système nerveux de l'homme et vertèbres. Instituto Ramon y Cajal, Madrid. 2nd printing (1972).

Reeves, T. M., and O. Steward (1986) Emergence of the capacity for LTP during reinnervation of the dentate gyrus-Evidence that abnormally shaped spines can mediate LTP. Exp. Brain Res. 65: 167175.

Sasaki-Sherrington, S., J. R. Jacobs, and J. K. Stevens (1984) Intracellular control of axial shape in non-uniform neurites: A serial electron microscopic analysis of organelles and microtubules in $\mathrm{AI}$ and AII retinal amacrine neurites. J. Cell Biol. 98: 1279-1290.

Scheibel, M. E., and A. B. Scheibel (1968) On the nature of dendritic spines. Report of a workshop. Commun. Behav. Biol. Part A, 1:231265.

Shepherd, G. M. (1979) The Synaptic Organization of the Brain, Oxford U. P., New York.

Shepherd, G. M., and R. K. Brayton (1987) Logic operations are properties of computer-simulated interactions between excitable dendritic spines. Neuroscience 21: 151-165.

Shepherd, G. M., R. K. Brayton, J. P. Miller, I. Segev, J. Rinzel, and
W. Rall (1985) Signal enhancement in distal cortical dendrites by means of interactions between active dendritic spines. Proc. Natl. Acad. Sci. USA 82: 2192-2195.

Spacek, J., and M. Hartmann (1983) Three-dimensional analysis of dendritic spines: I. Quantitative observations related to dendritic spine and synaptic morphology in ccrcbral and cercbcllar corticcs. Anat. Embryol. 167: 289-310.

Stevens, J. K., and J. Trogadis (1984) Computer assisted reconstruction from serial electron micrographs: A tool for systematic study of neuronal form and function. Annu. Rev. Neurobiol. 5: 341-369.

Stevens, J. K., J. Trogadis, and J. R. Jacobs (1988) Development and control of axial neurite form: A serial electron microscopic analysis. Neurol. Neurobiol. 37: 115-145.

Turner, D. A. (1984) Conductance transients onto dendritic spines in a segmental cable model of hippocampal neurons. Biophys. J. 46:8596.

Van Harreveld, A., and E. Fifkova (1975) Swelling of dendritic spines in the fascia dentata after stimulation of the perforant fibers as a mechanism of post-tetanic potentiation. Exp. Neurol. 49: 736-749.

Wenzel, J., W. Kirsche, G. Kunz, H. Neumann, M. Wenzel, and E. Winkelmann (1973) Licht- und electronmikroskopische untersuchungen uber die dendritenspines an pyramiden-neuronen des hippocampus [(CA1) bei der ratte]. J. Hirnforsch. 13: 388-408.

Wenzel, J., C. Schmidt, G. Duwe, W. G. Skrebitz, and I. Kudrjats (1985) Stimulation-induced changes of the ultrastructure of synapses in hippocampus following posttetanic potentiation. J. Hirnforsch. 26: 573-583.

Westrum, L. E., and T. W. Blackstad (1962) An electron microscopic study of stratum radiatum of the rat hippocampus (Regio superior, CA1) with particular emphasis on synaptology. J. Comp. Neurol. 119: 281-309.

Westrum, L. E., D. H. Jones, E. G. Gray, and J. Barron (1980) Microtubules, dendritic spines and spine apparatuses. Cell Tissue Res. 208: 171-181.

Wilson, C. J. (1984) Passive cable properties of dendritic spines and spiny neurons. J. Neurosci. 4: 281-297.

Wilson, C. J., P. M. Groves, S. T. Kitai, and J. C. Linder (1983) Threedimensional structure of dendritic spines in the rat neostriatum. $\mathrm{J}$. Neurosci. 3: 383-398. 